\title{
Experience with counterpulsation in cardiac surgical patients
}

\author{
G. H. SMITH AND W. E. MORGAN \\ From Sheffield Cardiothoracic Unit, Northern General Hospital, Sheffield
}

At Sheffield Regional Cardiothoracic Unit, the AVCO intra-aortic balloon pump has been used on 25 occasions in 21 months. Of the 25 patients, 12 survived and left hospital. The procedure is particularly beneficial in patients who have suffered some failure of myocardial protection during operation and to those who are suffering from acute ischaemia or the sequelae of myocardial infarction. The place of preoperative counterpulsation is discussed. Patients with long-standing cardiac disease who have emergency surgery benefit less from counterpulsation. Those patients with chronic ischaemic damage to the heart have nothing to gain from the use of counterpulsation.

The Sheffield Regional Cardiothoracic Unit obtained an AVCO intra-aortic balloon pump in 1974. Since that time, 25 patients have had the balloon inserted as a means of circulatory support and this group of patients is the subject of this report.

\section{Patients and methods}

The details of the 25 patients undergoing counterpulsation are set out in the Table.

\section{INDICATIONS FOR SUPPORT BY COUNTERPULSATION}

All patients who had cardiogenic shock which had failed to respond to the usual treatment were considered for the insertion of the intra-aortic balloon and treatment by counterpulsation. No distinction was made between patients with right and left ventricular failure. These patients were usually under surgical care but several were initially seen on medical wards. Cardiogenic shock was diagnosed when there was persistently low arterial blood pressure of below $80 \mathrm{mmHg}$ systolic, urine output below $0.5 \mathrm{ml} / \mathrm{kg}$ body weight per hour, and persistently cold skin, associated with mean atrial pressures in the range of 20 to $30 \mathrm{mmHg}$. Cardiac output measurements were not made. In all patients, cardiogenic shock was initially treated for at least one hour usually by means of an intravenous infusion of adrenaline or noradrenaline. Persistent failure of the blood pressure to rise above $80 \mathrm{mmHg}$ systolic and persistently low urine output and skin Received for publication 14 July 1976 temperature led to the insertion of the intraaortic balloon and treatment by counterpulsation.

TECHNIQUES OF INSERTION AND REMOVAL

In our experience the technique described by Kantrowitz et al. (1968) was reliable and applicable to all patients. The common femoral artery is exposed in the groin and a $12 \mathrm{~mm}$ Dacron graft is sewn onto the artery using 5/0 Prolene suture so as to form a prosthetic 'side arm' to the artery. The $30 \mathrm{ml}$ balloon is then inserted into this side arm and advanced into the descending thoracic aorta. A thick suture tied around the tube graft then allows the balloon to lie in the arterial system without blood loss. This small operation usually takes about 25 to 30 minutes and may be performed under local anaesthesia. Removal of the balloon is easily performed and the side arm is then either trimmed and sutured or doubly ligated very close to the artery.

\section{MONITORING OF PATIENTS RECEIVING COUNTERPULSATION}

Most of our patients who required counterpulsation had had an open heart operation. Consequently these patients had a left atrial pressure line as well as a right atrial pressure line, arterial cannula, and urinary catheter. The usual indirect indices of cardiac output were measured but in no case was the cardiac output measured directly. In this group of very ill patients, it is easy to allow too many monitoring devices and cables to accumulate around the patient; we found that the pressures and electrocardiogram were best recorded on a 
single instrument and that the control of the counterpulsation pump was best achieved by a 'jump' lead from this monitor.

\section{Results}

Of the 25 patients who were subjected to counterpulsation, 12 left hospital alive $(48 \%)$. Of those patients who died, 4 did so some time after showing an improvement with counterpulsation which persisted and allowed the balloon to be removed. Only 2 patients failed to show any improvement with counterpulsation.

Several groups, each requiring counterpulsation for a different reason, may be identified in this series of patients.

\section{(1) PREOPERATIVE COUNTERPULSATION}

(Cases 4, 17, 22, 25)

Four patients had the balloon inserted before operation. Two of these had an acute post-infarction ventricular septal defect (Cases 4 and 25) and were in very severe low output state; these patients subsequently underwent surgery successfully after counterpulsation for a period of 37 hours in one and 48 hours in the other. Another patient had a myocardial infarct with cardiogenic shock (Case 22) and responded well initially to counterpulsation. He died 48 hours later while being transferred for studies in the catheterisation room, and it is likely that the machine was not properly managed at the time of transfer. The remaining patient with severe multiple valve disease (Case 17) had the balloon inserted 18 hours before successful operation.

In each case there was an improvement in tissue perfusion which was often slow to start, occurring about 90 minutes after insertion of the balloon. Arterial blood pressure did not usually alter but skin temperature and urinary output rose and the patients' cerebration and metabolic state altered dramatically. When operation was undertaken, the patients were in a normal metabolic state and their morale was usually good.

In this subgroup, 3 of 4 patients survived and left hospital.

\section{(2) EMERGENCY VALVE OPERATIONS}

(Cases 2, 6, 7, 8, 9, 12, 21, 23)

Each of these patients came into hospital critically ill after a period of rapid deterioration at home or in

Table Details of patients undergoing counterpulsation

\begin{tabular}{|c|c|c|c|c|c|c|}
\hline $\begin{array}{l}\text { Case } \\
\text { No. }\end{array}$ & $\begin{array}{l}\text { Age } \\
(y)\end{array}$ & Sex & Nature of disease and operation & $\begin{array}{l}\text { Duration of } \\
\text { assistance }\end{array}$ & Outcome & Comments \\
\hline 1 & $\begin{array}{l}14 \\
35\end{array}$ & $\mathbf{F}$ & $\begin{array}{l}\text { Routine repair tetralogy of Fallot } \\
\text { Emergency MVR (clotted } \\
\text { prosthesis) }\end{array}$ & $\begin{array}{l}22 \mathrm{~h} \\
12 \mathrm{~h}\end{array}$ & $\begin{array}{l}\text { Death } \\
\text { Alive }\end{array}$ & $\begin{array}{l}\text { RV failure ? divided coronary artery } \\
\text { Previous MVR, AVR, TVR; infected prosthesis }\end{array}$ \\
\hline 3 & 66 & $\mathbf{M}$ & $\begin{array}{l}\text { Ventricular aneurysm, post- } \\
\text { infarction VSD; infarctectomy }\end{array}$ & $60 \mathrm{~h}$ & Alive & Chronic lung disease; hypoxia \\
\hline 4 & 59 & $\mathbf{M}$ & Post-infarction VSD & $96 \mathrm{~h}$ & Alive & $\begin{array}{l}\text { Preoperative support; required bilateral } \\
\text { below-knee leg amputation }\end{array}$ \\
\hline $\begin{array}{l}5 \\
6\end{array}$ & $\begin{array}{l}52 \\
38\end{array}$ & $\begin{array}{l}\mathbf{M} \\
\mathbf{M}\end{array}$ & $\begin{array}{l}\text { CABG + AVR } \\
\text { Urgent AVR, TVR }\end{array}$ & $\begin{array}{r}40 \mathrm{~h} \\
100 \mathrm{~h}\end{array}$ & $\begin{array}{l}\text { Alive } \\
\text { Late death }\end{array}$ & $\begin{array}{l}\text { LVF postoperatively; proven infarct } \\
\text { Liver failure; previous MVR }\end{array}$ \\
\hline 7 & 50 & $\mathbf{M}$ & Emergency MVR & $19 \mathrm{~h}$ & Alive & RVF; previous open repair MV \\
\hline 8 & 63 & $\mathbf{M}$ & Emergency MVR & $72 \mathrm{~h}$ & Late death & Hepatic cirrhosis; long-standing disease \\
\hline 9 & 54 & $\mathbf{M}$ & Emergency MVR & $90 \mathrm{~h}$ & Death & Unable to wean \\
\hline 10 & 54 & $\mathbf{F}$ & Routine AVR, MVR & $2 \mathrm{~d}$ & Late death & $\begin{array}{l}\text { Coronary atheroma prevented adequate } \\
\text { perfusion of myocardium during operation }\end{array}$ \\
\hline 11 & 62 & $\mathbf{F}$ & Routine MVR & $3 \mathrm{~d}$ & Late death & Infarct before operation \\
\hline 12 & 38 & $\mathbf{M}$ & Emergency AVR & $40 \mathrm{~h}$ & Death & $\begin{array}{l}\text { Previous prosthesis infected; large septal } \\
\text { abscess; heart block }\end{array}$ \\
\hline 13 & 43 & $\mathbf{M}$ & Emergency CABG $\times 2$ & $1 \mathrm{~d}$ & Alive & Probably evolving myocardial infarction \\
\hline 14 & 51 & $\mathbf{M}$ & Emergency $\mathrm{CABG} \times 2$ & $1 \mathrm{~d}$ & Alive & Evolving myocardial infarction \\
\hline 15 & 59 & $M$ & Routine AVR & $24 \mathrm{~h}$ & Alive & Right coronary disease, arrhythmias \\
\hline 16 & 55 & $\mathbf{M}$ & Routine AVR & $20 \mathrm{~h}$ & Death & $\begin{array}{l}\text { Diseased coronary arteries with abnormal } \\
\text { distribution }\end{array}$ \\
\hline 17 & 48 & $\mathbf{F}$ & Emergency AVR, MVR, TA & $40 \mathrm{~h}$ & Alive & Preoperative assistance \\
\hline 18 & 52 & $\mathbf{M}$ & $\mathrm{CABG} \times 3$ & $1 \mathrm{~d}$ & Alive & Incomplete endarterectomy LAD $\rightarrow$ infarct \\
\hline 19 & 57 & $\mathbf{M}$ & $\mathrm{CABG} \times 3$ & $12 \mathrm{~h}$ & Alive & Possible myocardial infarct \\
\hline 20 & 60 & $\mathbf{M}$ & Urgent LV aneurysmectomy & $1 \mathrm{~h}$ & Death & $\begin{array}{l}\text { Small aneurysm, extensive chronic damage to } \\
\text { left ventricle }\end{array}$ \\
\hline 21 & 58 & $M$ & Emergency MVR & $24 \mathrm{~h}$ & Death & Extensive visceral damage \\
\hline 22 & 50 & $\mathbf{M}$ & Myocardial infarct, in shock & $2 \mathrm{~d}$ & Death & $\begin{array}{l}\text { No operation, technical problems with } \\
\text { counterpulsation }\end{array}$ \\
\hline 23 & 51 & $\mathbf{M}$ & Emergency AVR & $18 \mathrm{~h}$ & Death & $\begin{array}{l}\text { Disruption of previous prosthesis } 24 \text { hours } \\
\text { before }\end{array}$ \\
\hline $\begin{array}{l}24 \\
25\end{array}$ & $\begin{array}{l}48 \\
59\end{array}$ & $\begin{array}{l}\mathbf{F} \\
\mathbf{M}\end{array}$ & $\begin{array}{l}\text { Urgent LV aneurysmectomy } \\
\text { Post-infarction VSD }\end{array}$ & $\begin{array}{r}2 \mathrm{~d} \\
90 \mathrm{~h}\end{array}$ & $\begin{array}{l}\text { Death } \\
\text { Alive }\end{array}$ & $\begin{array}{l}\text { Diffuse damage LV; new infarct } \\
\text { Preoperative support }\end{array}$ \\
\hline
\end{tabular}

MVR, mitral valve replacement; VSD, ventricular septal defect; CABG, coronary artery bypass graft; AVR, aortic valve replacement TVR, tricuspid valve replacement; TA, tricuspid annuloplasty; RVF, right ventricular failure; LAD, left anterior descending coronary artery; LV, left ventricle; LVF, left ventricular failure. 
another hospital. Most were semiconscious and uraemic on arrival and had persistently low blood pressures. Four patients in this group underwent emergency mitral valve replacement after many years of symptoms and deterioration; all 4 had been in hospital for some days before transfer to the unit; one patient had had haematemesis and another (Case 12) was jaundiced.

At operation, myocardial performance was not significantly improved after bypass in any of these patients. In all, the balloon was inserted during the operation after a period of one hour in which catecholamine infusion, correction of acidosis and arrhythmias had manifestly failed to improve cardiac function.

The average duration of counterpulsation after operation was 32 hours. Six patients were successfully weaned from support but 2 died subsequently. Two patients failed to support a circulation even with counterpulsation. Of the 4 patients undergoing emergency mitral valve replacement, only 2 survived to leave hospital.

\section{(3) DAMAGE TO MYOCARDIUM DURING} OPERATION (Cases 5, 10, 15, 16, 18, 19)

In each of these cases, operation was routinely performed, but during the procedure technical problems were encountered which rendered preservation of myocardial function difficult.

Case 5, who underwent aortic valve replacement, with coronary artery bypass grafting and endarterectomy, had an intraoperative myocardial infarct, presumably as a result of an inadequate endarterectomy. In Cases 10,15, and 16, unexpected severe coronary arterial disease was encountered during aortic valve replacement rendering adequate coronary perfusion impossible. In each case, counterpulsation had to be started before the patient could be weaned from bypass. Our present policy of profound topical cardiac hypothermia results from this experience. Cases 18 and 19 were patients having multiple vein grafts applied for relief of angina. In Case 18, an endarterectomy had to be performed on the left anterior descending artery; a documented infarct and left ventricular failure probably resulted from incomplete endarterectomy. The other patient had a long and difficult operation to revascularise a poorly functioning ventricle, and it is probable that further myocardial damage occurred during the operation. In these 2 patients, counterpulsation was started 90 minutes and 300 minutes respectively after coming off bypass.

In this group, one death occurred during counterpulsation and one late death followed a satisfactory initial response.
(4) OPERATION FOR EVOLVING MYOCARDIAL INFARCTION (Cases 13 and 14)

Both of these patients underwent revascularisation surgery during an episode of prolonged severe chest pain associated with electrocardiographic abnormalities suggestive of an early infarct. In each case, when the chest was opened the cardiac output was very low and the left atrial pressure was high. After bypass, some improvement in ventricular function occurred but was inadequate to support a spontaneous circulation until the balloon was inserted. Both patients survived and left hospital.

(5) SALVAGE OPERATIONS FOR CHRONICALLY DAMAGED HEARTS (Cases 3, 20, 24)

Each of these patients was known to have a left ventricular aneurysm and had undergone acute deterioration a short time before operation. In each a large discrete ventricular aneurysm was found, but after resection, myocardial performance was inadequate to maintain a satisfactory circulation. Counterpulsation in two of the three cases was ineffective; these patients could not be weaned from bypass and died. At necropsy, diffuse chronic damage of the left ventricle was found.

\section{(6) MISCELlaneOUS CASES}

Case 1 had had a total repair of tetralogy of Fallot and had done well for 12 hours. Cardiac output then fell and remained low in spite of treatment. After 48 hours, when the patient was moribund, the balloon was inserted but counterpulsation produced only a temporary response.

Case 11, a patient of 62 years, underwent a routine mitral valve replacement. No technical difficulties or failure of myocardial preservation occurred. Cardiac output fell after operation and failed to respond to counterpulsation which was started 6 hours after operation and continued for 3 days. At necropsy there were signs of previous infarction of the left ventricle, which was thought to have occurred before operation.

\section{Discussion}

Intra-aortic balloon counterpulsation has been shown to increase the blood supply to ischaemic myocardium (Gill et al., 1973) and also to reduce left ventricular work in the failing heart (Powell et al., 1970). The clinical value of these haemodynamic changes has been shown by several groups of workers who have reported their results. The immediate response and short and long-term results of treatment with counterpulsation have been reported in patients who are shocked after myocardial infarc- 
tion (Dunkman et al., 1972; Scheidt et al., 1973), and those who have poor cardiac function after operation (Buckley et al., 1973). Counterpulsation has also been used in the management of patients with complications of myocardial infarction (Buckley et al., 1973).

The group of patients reported here has been treated during a 21-month period at the Sheffield Cardiothoracic Unit. During this time approximately 500 open heart operations were performed in the Sheffield Hospitals. Counterpulsation has been used in 25 patients and certain types of patient may be identified who have most to gain from the support offered. Counterpulsation appears to be of value in patients who arrive in terminal stages of cardiac disease associated with profound metabolic disturbances and incipient organ failure. In our experience, patients suffering from the mechanical sequelae of myocardial infarction, such as an acute ventricular septal defect, do well as do some patients in the terminal stage of valvular heart disease. The conduct of the anaesthetic, perfusion, and operative procedure is simplified and provided that correction of the defect is achieved, the outlook is good. Similarly a good immediate response and late result were achieved in patients who sustained acute left ventricular myocardial damage during operation. Identical experience has been reported by Buckley et al. (1973).

The results of using counterpulsation were poor when chronic damage to the left ventricle had preceded operation and were very bad in those patients who had end-stage severe mitral valve disease, usually associated with chronic pulmonary vascular disease. Both of the patients who survived counterpulsation after emergency mitral valve operations were young and had had problems which, though severe, had been of short duration and which had begun in hospital.

One of these patients (Case 7) is of particular interest. This man of 50 years had had an open mitral valvotomy with freeing of fused chordae 10 days previously. Investigation after the development of sudden pulmonary oedema showed gross mitral regurgitation. At operation, there was necrosis of the tip of the anterior papillary muscle and both mitral leaflets were flail. Mitral valve replacement was performed and when bypass was discontinued, there was a very high pulmonary artery pressure and a high right atrial pressure together with a low left atrial pressure and inadequate cardiac output. The patient deteriorated further after operation and the counterpulsation was started in a desperate attempt to save his life. Improvement was dramatic and may have been the result of improved oxygen delivery to a failing high pressure right ventricle. The phasic flow pattern of the coronary arterial supply to the normal right ventricle has been shown to be mainly systolic in timing, whereas that to the normally functioning left ventricle is mostly diastolic (Fixler et al., 1973). Presumably a high pressure right ventricle has a supply similar to that of the left ventricle and the effect of counterpulsation in this instance was to improve the diastolic coronary blood flow to the right ventricle. Case 1, a patient with right ventricular failure after total repair of tetralogy of Fallot, might have improved also had counterpulsation been started earlier.

Some authors have stated that counterpulsation was not a useful procedure (Effler, 1975) and was unnecessary in surgical practice. While certain of the indications for counterpulsation are avoidable, especially by adequate myocardial protection during operation, there remains a group of patients which presents to the cardiologist or surgeon with acute but reversible damage to the myocardium. Surgical correction cannot always result in sufficient immediate improvement in function to maintain an adequate circulation without assistance. The use of counterpulsation in this group of patients has had encouraging results and has undoubtedly saved patients who would otherwise have died.

We have found that the AVCO intra-aortic balloon pump is a most reliable instrument and is easy to use and to understand. The nursing staff, in particular, have felt happy to manage patients who have been treated with it.

We thank Mr. D. G. Taylor for permission to report Cases 1 and 23 who were admitted to hospital under his care.

\section{References}

Buckley, M. J., Mundth, E. D., Daggett, W. M., Gold, H. K., Leinbach, R. C., and Austen, W. G. (1973). Surgical management of ventricular septal defects and mitral regurgitation complicating acute myocardial infarction. Annals of Thoracic Surgery, 16, 598.

Dunkman, W. B., Leinback, R. C., Buckley, M. J., Mundth, E. D., Kantrowitz, A. R., Austen, W. G., and Sanders, C. A. (1972). Clinical and haemodynamic results of intraaortic balloon pumping and surgery for cardiogenic shock. Circulation, 46, 465.

Effler, D. B. (1975). In discussion of Bregman, D., Parodi, E. N., Edie, R. N., Bowman, F. O., Reempsma, K., and Malm, J. R. Intra-operative unidirectional intra-aortic balloon pumping in the management of left ventricular power failure. Fournal of Thoracic and Cardiovascular Surgery, 70, 1024.

Fixler, D. E., Archie, J. P., Ullyot, E. J., Buckberg, G. D., and Hoffman, J. I. E. (1973). Effects of acute right ventricular systolic hypertension on regional myocardial blood 
flow in anesthetised dogs. American Heart fournal, 85, 491. Gill, C. C., Wechsler, A. S., Newman, G. E., and Oldham, H. N., Jr. (1973). Augmentation and redistribution of myocardial blood flow during acute ischemia by intraaortic balloon pumping. Annals of Thoracic Surgery, 16, 445 .

Kantrowitz, A., Phillips, S. J., Butner, A. N., Tjonneland, S., and Haller, J. D. (1968). Technique of femoral artery cannulation for phase shift balloon pumping. Fournal of Thoracic and Cardiovascular Surgery, 56, 219.

Powell, W. J., Jr., Daggett, W. M., Magro, A. E., Bianco, J. A., Buckley, M. J., Sanders, C. A., Kantrowitz, A. R., and Austen, W. G. (1970). Effects of intra-aortic balloon counterpulsation on cardiac performance, oxygen consumption and coronary blood flow in dogs. Circulation Research, 26, 753.

Scheidt, S., Wilner, G., Mueller, H., Summers, D., Lesch, M., Wolff, G., Krakaner, J., Rubenfire, M., Fleming, P., Noon, G., Oldham, H., Killip, T., and Kantrowitz, A. (1973). Intra-aortic balloon counterpulsation in cardiog enic shock; report of a co-operative trial. New England fournal of Medicine, 288, 979.

Requests for reprints to G. H. Smith, Esq., F.R.C.S., Sheffield Cardiothoracic Unit, Northern General Hospital, Sheffield S5 7AU. 